\title{
Influence of Leaf Area Index on the Radiometric Resistance to Heat Transfer
}

\author{
Lei Zhao ${ }^{1,2} \cdot$ Xuhui Lee ${ }^{1,2} \cdot$ Andrew E. Suyker ${ }^{3}$. \\ Xuefa Wen ${ }^{4}$
}

Received: 21 November 2014 / Accepted: 14 July 2015 / Published online: 1 September 2015

C) Springer Science+Business Media Dordrecht 2015

\begin{abstract}
Sensible heat flux is an important component of the surface energy balance. Land surface models often use the radiative surface temperature instead of the aerodynamic temperature to predict the surface sensible flux, because the former is much easier to observe by remote sensing or to compute from the surface energy balance equation. Here, measurements from 44 FLUXNET sites are used to examine the stability and leaf area index (LAI) dependence of the radiometric resistance, a resistance that should be included in the bulk transfer method if the radiometric temperature is used for the flux calculation. Results show that the radiometric resistance is much higher under stable conditions than under unstable conditions. In unstable conditions, the radiometric resistance is highly sensitive to $L A I$, decreasing exponentially as $L A I$ increases. Omission of the radiometric resistance from the bulk transfer method causes a large overestimation in the sensible heat flux, especially for low-LAI surfaces and under unstable conditions.
\end{abstract}

Keywords Aerodynamic temperature - Leaf area index - Radiative surface temperature · Radiometric resistance $\cdot$ Sensible heat flux

Electronic supplementary material The online version of this article (doi:10.1007/s10546-015-0070-4) contains supplementary material, which is available to authorized users.

Lei Zhao

lei.zhao@yale.edu

1 Yale-NUIST Center on Atmospheric Environment, Nanjing University of Information, Science and Technology, Nanjing 210044, China

2 School of Forestry and Environmental Studies, Yale University, New Haven, CT 06511, USA

3 School of Natural Resources, University of Nebraska, Lincoln, NE 68583, USA

4 Key Laboratory of Ecosystem Network Observation and Modeling, Institute of Geographic Sciences and Natural Resources Research, Chinese Academy of Sciences, Beijing, China 


\section{Introduction}

The bulk transfer equation (Garratt and Hicks 1973; Monteith 1973; Garratt and Francey 1978 ) is a widely employed method for estimating sensible heat flux $(H)$ in land-surface models (LSMs) (Mahrt and Vickers 2004), i.e.,

$$
H=\rho C_{p} \frac{\theta_{0 h}-\theta_{a}}{R_{a h}},
$$

where $\rho$ is air density, $C_{p}$ is the specific heat capacity of air at constant pressure, $\theta_{a}$ is the potential temperature at a reference height in the surface layer, $\theta_{0 h}$ is the effective aerodynamic temperature of the surface, and $R_{a h}$ is a heat transfer resistance for the pathway from $\theta_{0 h}$ to $\theta_{a}$. The heat transfer resistance, $R_{a h}$, can be formulated as

$$
R_{a h}=\frac{\left[\ln \left(\frac{z-d}{z_{0}}\right)-\Psi_{M}\right]\left[\ln \left(\frac{z-d}{z_{h}}\right)-\Psi_{H}\right]}{k^{2} u},
$$

where $k$ is the von Karman constant, $z$ is the measurement height of $\theta_{a}$ and wind speed $u, d$ is the displacement height, $z_{0}$ is the aerodynamic roughness length, $z_{h}$ is the thermal roughness length, and $\Psi_{M}$ and $\Psi_{H}$ are the stability correction functions for momentum and heat, respectively. Note that $z_{0}$ and $z_{h}$ are profile characteristics. The implicit assumption is that the standard Monin-Obukhov functions are valid down to the top of the roughness sublayer, but are invalid below this level.

The accuracy of Eq. 1 depends on how the surface temperature is chosen. Use of $R_{a h}$ defined in Eq. 2 requires $\theta_{0 h}$ to be the effective aerodynamic temperature at $z=d+z_{h}$. The two roughness lengths in Eq. 2 are typically different (Garratt and Hicks 1973), and their ratio is a function of surface stiffness and the roughness Reynolds number (Molder and Lindroth 2001). A universal and robust parametrization of $z_{h}$ across a large variety of land-cover types does not exist, and so two alternative approaches are used to remove $z_{h}$ from the bulk transfer method. In one approach, $z_{h}$ is assumed to be equal to $z_{0}$, and $R_{a h}$ is simply reduced to the aerodynamic resistance $R_{a}$,

$$
R_{a}=\frac{\left[\ln \left(\frac{z-d}{z_{0}}\right)-\Psi_{M}\right]\left[\ln \left(\frac{z-d}{z_{0}}\right)-\Psi_{H}\right]}{k^{2} u},
$$

while in the second approach, $R_{a h}$ is expressed as a combination of the aerodynamic resistance, $R_{a}$, and the excess resistance, $R_{e x}$,

$$
R_{a h}=R_{a}+R_{e x} .
$$

In neutral stability, manipulation of Eqs. $2-4$ gives

$$
R_{e x}=\frac{\operatorname{In}\left(z_{0} / z_{h}\right)}{k u_{*}}
$$

where $u_{*}$ is the friction velocity (Garratt and Hicks 1973).

One difficulty with the above formulations is that $\theta_{0 h}$ cannot be measured directly. In field campaigns, this temperature is usually inferred from extrapolation of the temperature profile to $z_{0}$ or $z_{h}$ according to Monin-Obukhov similarity theory (Thom et al. 1975; Garratt and Francey 1978). Although $z_{0}$ and $z_{h}$ are profile characteristics, the corresponding roughness elements typically lie in the roughness sublayer, where the similarity theory does not hold. Therefore, this extrapolation of the temperature profile is an important source of 
error. In addition, vertical temperature profiles are generally not available in remote-sensing applications (Kustas et al. 2003; Matsushima 2005; Kustas and Anderson 2009; Mu et al. 2011). For these reasons, in practice, $\theta_{0 h}$ is usually approximated by the surface radiative temperature $\theta_{s}$, which can be measured by remote-sensing techniques or computed from the surface energy balance equation (Sun and Mahrt 1995). Use of $\theta_{s}$ in place of $\theta_{0 h}$ for the bulk parametrization is especially attractive to modellers, because in almost all land-surface models, $\theta_{s}$ is an important prognostic variable derived from solution of the surface energy balance equation.

Previous researchers have reported that $\theta_{s}$ and $\theta_{0 h}$ can be very different, in both stable and unstable conditions, and a simple substitution of $\theta_{s}$ for $\theta_{0 h}$ can result in systematic high biases in the prediction of sensible heat flux (Choudhury et al. 1986; Beljaars and Holtslag 1991; Hall et al. 1992). To date, efforts to remediate this problem have fallen into three categories:

- Prediction of $\theta_{0 h}$ from $\theta_{s}$. In some studies, the relationship between the radiative and the effective aerodynamic temperature is expressed as a function of $z_{h}$ (Garratt and Francey 1978; Brutsaert and Sugita 1992). Beljaars and Holtslag (1991) suggested that the relationship should depend on the temperature scale $\theta_{*}$ (defined as $H / \rho C_{p} u_{*}$ ) and thermal stability. Mahrt and Vickers (2004) and Matsushima (2005) found that $\theta_{s}-\theta_{0 h}$ is related to solar radiation and leaf area index $(L A I)$.

- Introduction of a new roughness length $z_{r}$. Here, $z_{n}$ is called the "radiometric roughness length," being smaller than $z_{h}$ by up to a few orders of magnitude. In a number of studies, the difference between the radiometric roughness length $z_{r}$ and $z_{0}$ is represented using a redefined $\mathrm{kB}^{-1}$ parameter $\left(k B^{-1}=\ln \frac{z_{0}}{z_{r}}\right)$, instead of the standard formulation $\left(k B^{-1}=\ln \frac{z_{0}}{z_{h}}\right)$; this modified $\mathrm{kB}^{-1}$ parameter is related to the roughness Reynolds number and $\theta_{s}$ (Kustas et al. 1989; Sugita and Brutsaert 1990; Stewart et al. 1994; Sun and Mahrt 1995; Troufleau et al. 1997; Verhoef et al. 1997; Yang et al. 2003) or is physically modelled based on the "localized near-field" Lagrangian theory (McNaughton and Vandenhurk 1995; Su et al. 2001). These studies show that $\mathrm{kB}^{-1}$ behaves erratically, and that a universal parametrization may be unattainable.

- To add an extra resistance, $R_{r}$ : this "radiometric resistance" is added to the bulk transfer formulation (Lhomme et al. 1988; Stewart et al. 1994), such that

$$
H=\rho C_{p} \frac{\theta_{s}-\theta_{a}}{R_{r}+R_{a h}}
$$

where $R_{a h}=R_{a}+R_{e x}$. According to Lhomme et al. (1988) and Stewart et al. (1994), $R_{r}$ is generally larger than $R_{a h}$.

A number of studies have suggested the importance of $L A I$ and thermal stability in controlling the biases caused by substituting $\theta_{s}$ for $\theta_{0 h}$. Beljaars and Holtslag (1991) found that $\theta_{0 h}-\theta_{s}$ varies from $6 \mathrm{~K}$ in stable conditions to $-6 \mathrm{~K}$ in unstable conditions. Both Troufleau et al. (1997) and Verhoef et al. (1997) found that, for sparse vegetation (low LAI), $\mathrm{kB}^{-1}$ shows a large mean value and a large variation. Mahrt and Vickers (2004) reported a significant positive linear dependence of $\theta_{s}-\theta_{0 h}$ on solar radiation and a negative dependence on LAI. Solar radiation partly influences the heat transfer through its effect on thermal stability. These relationships have been established with observations over several surface types, including a bare-soil site, three grassland sites, a cropland site, and four forest sites. Kustas et al. (2007) found that the slopes and intercepts of the linear regressions that Mahrt and Vickers (2004) proposed vary considerably when applied to a wider range of landscapes (LAI 0.5-3.0) and meteorological conditions. Similarly, the correction factor proposed by Matsushima (2005) for $\theta_{s}-\theta_{0 h}$ has a strong correlation with $L A I$. 
Recently, Zheng et al. (2012) developed new formulations of the roughness lengths using a green vegetation fraction derived from the remotely sensed normalized difference vegetation index, the latter being known to be a good estimator of LAI. The stability effects on the radiometric resistance $R_{r}$ or $\mathrm{kB}^{-1}$ have been somewhat overlooked in previous studies (Stewart et al. 1994; Troufleau et al. 1997; Matsushima 2005); for example, Matsushima (2005) showed that the effects of atmospheric stability in the surface layer can be ignored in the parametrized radiometric roughness length or temperature "correction" factors.

The primary objective of the present study is to revisit the roles of $L A I$ and thermal stability in the bulk formulation (Eq. 6). Our focus is on patterns of the radiometric resistance $R_{r}$ across a diverse set of ecosystems and local climates. Previous studies have been restricted to a small number of sites (one to nine). Here, we deploy data obtained from 44 sites in the FLUXNET network. Previous reports have confirmed a large variation in hourly $\mathrm{kB}^{-1}$ values (Troufleau et al. 1997; Verhoef et al. 1997), partly due to the high sensitivity of $\mathrm{kB}^{-1}$ to measurement errors in the micrometeorological variables (Verhoef et al. 1997). Here, we examine how mean resistance varies across the sites, instead of using 30-min values at a specific site as done in previous studies. The advantage of this site-mean approach is that it identifies patterns caused by land-cover differences, compared with synoptic meteorological fluctuations and instrument noise. In addition, we provide an assessment of the prediction error in sensible heat flux caused by omission of $R_{r}$ from Eq. 6 .

\section{Data and Methods}

\subsection{Surface Observations}

We examine tower observations from 44 FLUXNET sites in the USA, Canada, and China (Table 1). FLUXNET is a global network of surface eddy-covariance towers, with the observations covering a large range of $u_{*}$ (site annual mean value $0.1-1.5 \mathrm{~m} \mathrm{~s}^{-1}$ ). Although $u_{*}$ is related to wind speed, the annual mean value can be viewed as a proxy of the surface roughness, having a high correlation with $z_{0}$ (linear correlation $=0.60$ ). We chose these sites because measurements of the longwave components of the surface radiation balance were available, in addition to the energy and momentum fluxes and micrometeorological variables, and for a sufficiently long time ( $>12$ months). They span a large range of $L A I$ (0 to 9$)$ and canopy height $(0.1$ to $33 \mathrm{~m})$, and are divided into four categories: 19 conifer forest sites (with nearly constant $L A I$ throughout the year), 12 deciduous forest sites (with seasonal $L A I$ change), 6 grassland sites (with seasonal $L A I$ change), and 7 cropland sites (with large $L A I$ changes between growing and nongrowing seasons). For each site, we selected one year of measurements and confined our analysis periods to December to February, and June to August, for the winter and summer seasons ( $>90 \%$ data coverage for each site for each season). We also separate the data into stable and unstable conditions. The original data are 30-min values for 40 sites; for four sites (site IDs: US-MMS, US-Ne1, US-Ne2, and US-Ne3; Table 1) only hourly measurements are available.

Except for the Mead irrigated cropland site in Nebraska (site ID US-Ne1, Table 1), we report all results as site mean values. At the Mead cropland site, high-frequency measurements of LAI were available from 2006 to 2012, showing large LAI changes within the growing season. To capture these seasonal variations, we analyzed the daily mean quantities for this site. 


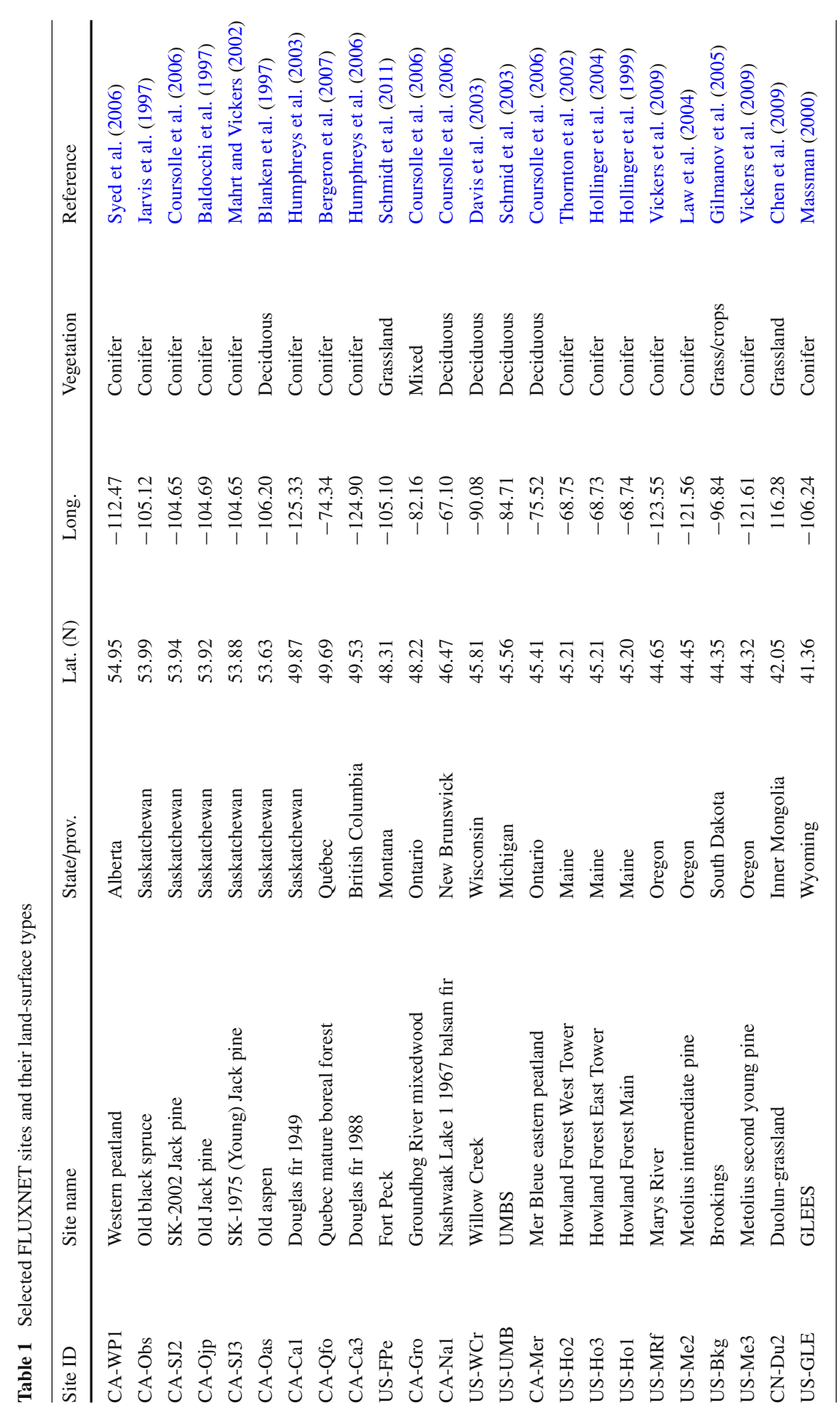




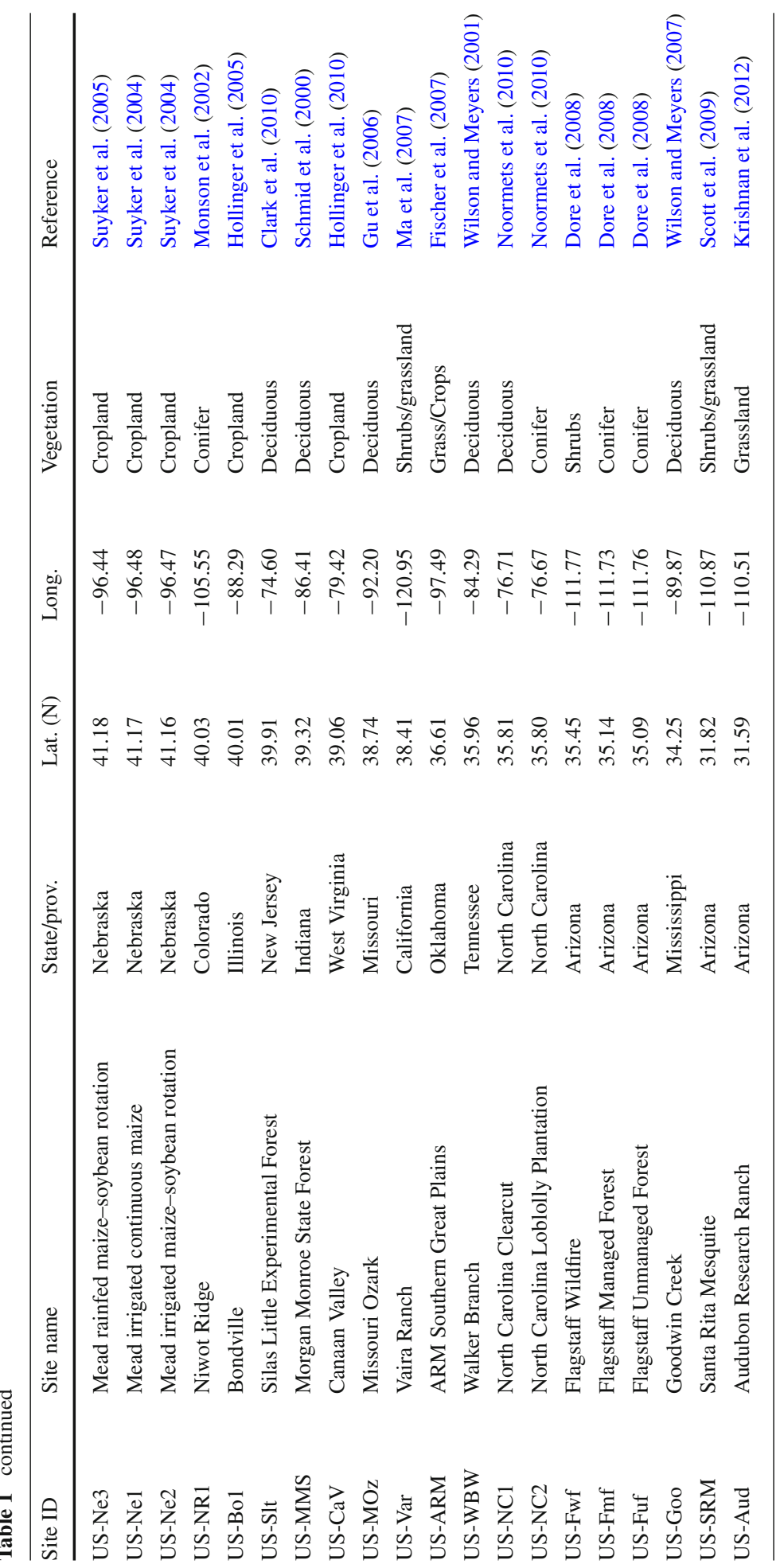


Fig. 1 Schematic of the resistance decomposition model for calculating the sensible heat flux, $H . \theta_{0 h}$ is the aerodynamic temperature at the thermal roughness height; $\theta_{0}$ is the aerodynamic temperature at the momentum roughness height

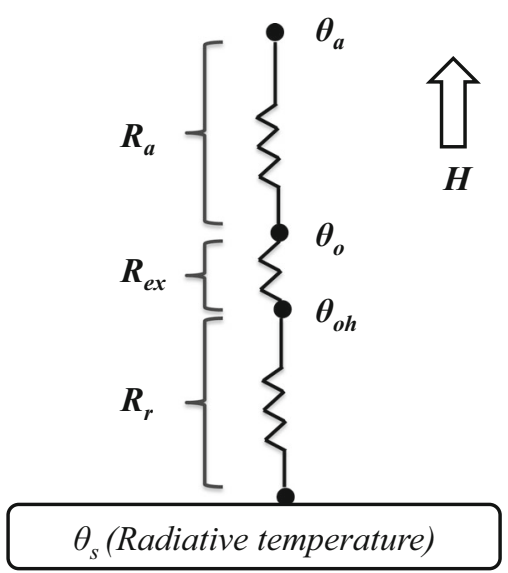

\subsection{Data Analysis}

We computed the half-hourly or hourly $R_{r}$ using Eq. 6, where the total heat resistance consists of three additive components (Fig. 1). The aerodynamic resistance $R_{a}$ was determined with Eq. 3, and the excess resistance $R_{e x}$ was approximated by

$$
R_{e x}=\frac{2}{k u_{*}}
$$

which indicates that $z_{0} / z_{h}=7.4$, a typical ratio for rough surfaces (Garratt 1994). The corresponding $k B^{-1}$ value is 2 . Making use of Eqs. 4, 6, and 7, we obtain an expression for computing $R_{r}$,

$$
R_{r}=\frac{\rho C_{p}\left(\theta_{s}-\theta_{a}\right)}{H}-R_{a}-\frac{2}{k u_{*}} .
$$

In Eqs. 2, 3, and 8, $H, \theta_{a}$, and $u_{*}$ were available from direct tower measurements, while $\theta_{s}, \rho$, $R_{a}$, and the stability correction factors $\Psi_{M}$ and $\Psi_{H}$ were calculated using measured variables, and $d$ and $z_{0}$ were assumed as $70 \%$ and $10 \%$ of the canopy height $(h)$, respectively. Note that $\Psi_{M}$ and $\Psi_{H}$ were calculated according to the Businger-Dyer formulation, though we tested other formulations of the stability correction functions (Brutsaert 1992), finding that the results obtained were insensitive to the choice of stability correction functions.

We separated the half-hourly or hourly data into stable and unstable conditions using the sign of the surface sensible heat flux. All observations with $H<-5 \mathrm{~W} \mathrm{~m}^{-2}$ were grouped into stable conditions, and all observations with $H>5 \mathrm{~W} \mathrm{~m}^{-2}$ were grouped into unstable conditions. Observations with $-5<H<5 \mathrm{~W} \mathrm{~m}^{-2}$ were considered as neutral or nearneutral conditions and were not used.

The surface radiative temperature $T_{S}$ was determined from the upward longwave radiation flux and corrected for the surface reflection of the downward longwave radiation flux, as

$$
T_{s}=\left[\frac{L_{\uparrow}-(1-\varepsilon) L_{\downarrow}}{\varepsilon \sigma}\right],
$$

where $L_{\uparrow}$ is the upward longwave radiative flux, $L_{\downarrow}$ is the downward longwave radiative flux, $\varepsilon$ is the surface emissivity (assumed to be 0.98 ), and $\sigma$ is the Stefan-Boltzmann constant. 


\section{Results and Discussion}

\subsection{Relations of Heat Resistances to $L A I$ Under Unstable Conditions}

Here, we provide a detailed examination of the resistances under unstable conditions. Previous studies have shown that the bulk formulation is much more uncertain under unstable conditions than under stable conditions. The excess resistance $R_{e x}$ shows no obvious dependence on $L A I$ (Fig. 2e, f). This resistance arises from the fact that heat is transferred by molecular diffusion through the laminar boundary layer on foliage in immediate contact with the surface, whereas momentum exchange is more efficient due to the existence of both viscous shear and form drag (Thom 1972). The insensitivity of $R_{e x}$ to $L A I$ suggests that $R_{e x}$ is controlled primarily by these processes at the leaf scale and is not affected by the amount or arrangement of foliage elements at the canopy scale.

The radiometric resistance $R_{r}$ shows a much stronger relationship with $L A I$ than does $R_{e x}$, with an exponential decay as $L A I$ increases (Fig. 2a, b). For small $L A I$ values $(L A I<1), R_{r}$ is 3.7 times larger than $R_{e x}$ in the summer and 1.4 times larger in the winter. An alternative interpretation is that the effective $z_{r}$ is much smaller than $z_{h}$ for sparse vegetation. Because at sites of larger $R_{r}$ the temperature difference $\theta_{s}-\theta_{0 h}$ should be larger in magnitude, our results are consistent with those of Mahrt and Vickers (2004). Using airborne measurements from the Southern Great Plains Experiment, these authors showed that $\theta_{s}-\theta_{0 h}$ can be described by the simple linear model

$$
\theta_{s}-\theta_{0 h}=C\left[S-C_{s}\left(L A I-L A I_{\mathrm{ref}}\right)\right],
$$

where $C$ and $C_{s}$ are positive regression coefficients, $S$ is the solar radiative flux, and the reference $L A I$ value $\left(L A I_{\text {ref }}\right)$ is approximately 1 . This expression illustrates that $\theta_{s}-\theta_{0}$ is large when $L A I$ is small. They also acknowledged that a more complex function of $L A I$ is required for very large $L A I$. The dependence on $S$ is explained by the fact that sunlit surfaces warm up more rapidly than the air at the roughness height.

The aerodynamic resistance $R_{a}$ behaves similarly to $R_{r}$ as $L A I$ changes (Fig. $2 \mathrm{c}, \mathrm{d}$ ), and in terms of magnitude, $R_{a}$ is comparable to $R_{r}$. The physical explanation of the exponential correlation between the $L A I$ and the aerodynamic resistance is connected to convection efficiency. High $L A I$ usually corresponds to aerodynamically rough surfaces; these surface can trigger large coherent eddies that are efficient in heat convection, whereas low- $L A I$ surfaces (grassland or fallow cropland) are more like bluff-rough surfaces that are less efficient in generating energetic eddies (Stewart et al. 1994; Voogt and Grimmond 2000).

\subsection{Summer Versus Winter}

There are seasonal differences in the three resistances (Table 2), with Fig. 2 showing that the general relationships with $L A I$ are similar between the summer and winter seasons. In the winter, when $L A I$ is smaller, the site-mean values of $R_{r}$ and $R_{a}$ are more scattered than in the summer (Fig. 2a-d). One reason is related to deciduous forest sites, which have low $L A I$ in the winter, but are still aerodynamically rough. Instead of assuming that $z_{0}$ is proportional to stand height, an improved parametrization (e.g., Raupach 1994) where $z_{0}$ is a function of both canopy height and $L A I$, may reduce the scatter.

In terms of magnitude, $R_{r}$ shows higher values in the winter than in the summer, and the other two resistances do not show strong seasonal differences. The $R_{r}$ seasonality is partly explained by $L A I$ changes. For the deciduous forest group, the average winter $L A I$ is low (1.5), and the average $R_{r}$ is $66 \mathrm{~s} \mathrm{~m}^{-1}$. In the summer, when the average $L A I$ increases to 

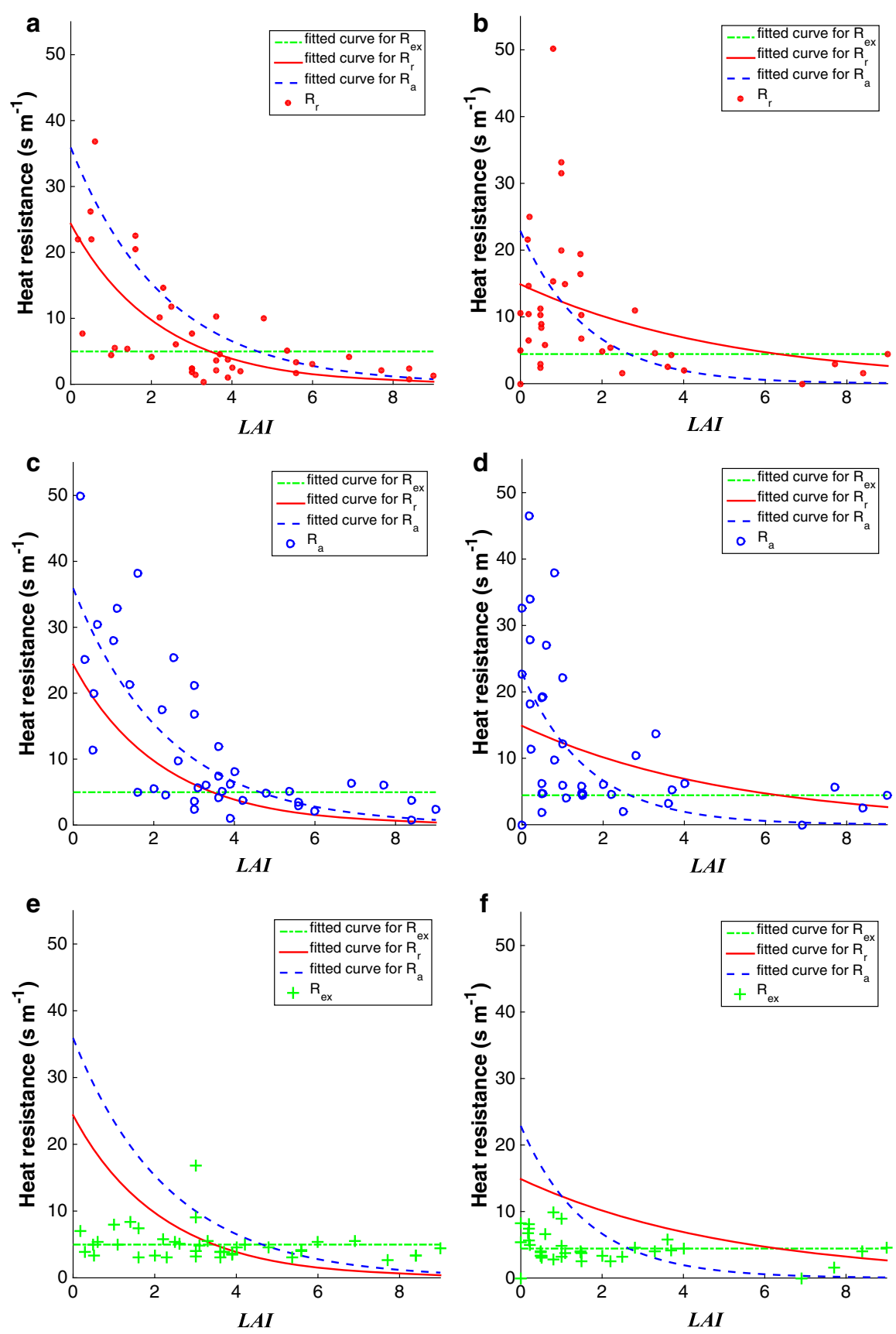

Fig. 2 Relationship between the three heat resistances and $L A I$ under unstable conditions. a, c, e summer; $\mathbf{b}, \mathbf{d}, \mathbf{f}$ winter. Each date point represents a site seasonal mean value. Lines are regression fits to the data: $R_{r}, y=24.4 \exp (-0.5 x)$ (summer), $y=14.9 \exp (-0.2 x)$ (winter); $R_{a}, y=35.9 \exp (-0.4 x)$ (summer), $y=22.9 \exp (-0.6 x)$ (winter); $R_{\text {ex }}, y=5 \mathrm{~s} \mathrm{~m}^{-1}$ (summer), $y=4 \mathrm{~s} \mathrm{~m}^{-1}$ (winter). For each stability class, the same fit lines are shown in the three panels. The first coefficient in the exponential functions has the dimensions of $\mathrm{s} \mathrm{m}^{-1}$ 
Table 2 Statistics of the three component resistances among all the sites

\begin{tabular}{|c|c|c|c|c|c|c|}
\hline \multirow[t]{2}{*}{ Veg. type } & \multirow[t]{2}{*}{ Season } & \multirow[t]{2}{*}{ Stability } & \multirow[t]{2}{*}{$L A I$} & \multirow{2}{*}{$\frac{R_{r}}{\text { Mean } \pm \text { s.e. }\left(\mathrm{s} \mathrm{m}^{-1}\right)}$} & \multirow{2}{*}{$\begin{array}{l}R_{a} \\
\text { Mean } \pm \text { s.e. }\left(\mathrm{sm}^{-1}\right)\end{array}$} & \multirow{2}{*}{$\begin{array}{l}R_{e x} \\
\text { Mean } \pm \text { s.e. }\left(\mathrm{sm}^{-1}\right)\end{array}$} \\
\hline & & & & & & \\
\hline \multirow[t]{4}{*}{ Deciduous } & \multirow[t]{2}{*}{ Summer } & Unstable & 4.1 & $4.3 \pm 09$ & $7.6 \pm 2.1$ & $5.5 \pm 1.2$ \\
\hline & & Stable & & $46.8 \pm 6.9$ & $54.8 \pm 7.6$ & $9.5 \pm 0.8$ \\
\hline & \multirow[t]{2}{*}{ Winter } & Unstable & 1.5 & $8.6 \pm 1.8$ & $9.3 \pm 3.1$ & $4.1 \pm 0.5$ \\
\hline & & Stable & & $78.3 \pm 9.7$ & $28.1 \pm 5.3$ & $6.1 \pm 0.6$ \\
\hline \multirow[t]{4}{*}{ Conifer } & \multirow[t]{2}{*}{ Summer } & Unstable & 4.0 & $6.4 \pm 1.8$ & $8.2 \pm 2.5$ & $4.1 \pm 0.2$ \\
\hline & & Stable & & $51.8 \pm 6.3$ & $66.5 \pm 6.0$ & $10.6 \pm 0.8$ \\
\hline & \multirow[t]{2}{*}{ Winter } & Unstable & 3.4 & $9.3 \pm 2.0$ & $9.2 \pm 2.4$ & $3.8 \pm 0.4$ \\
\hline & & Stable & & $59.8 \pm 9.4$ & $44.0 \pm 5.9$ & $7.3 \pm 0.8$ \\
\hline \multirow[t]{4}{*}{ Grass/shrub } & \multirow[t]{2}{*}{ Summer } & Unstable & 1.2 & $17.5 \pm 5.2$ & $27.7 \pm 3.7$ & $6.0 \pm 0.5$ \\
\hline & & Stable & & $31.8 \pm 1.6$ & $62.6 \pm 8.3$ & $8.8 \pm 0.9$ \\
\hline & \multirow[t]{2}{*}{ Winter } & Unstable & 0.3 & $16.9 \pm 7.5$ & $20.6 \pm 5.7$ & $5.4 \pm 1.4$ \\
\hline & & Stable & & $56.0 \pm 17.8$ & $44.2 \pm 11.9$ & $7.1 \pm 1.8$ \\
\hline \multirow[t]{4}{*}{ Crop } & \multirow[t]{2}{*}{ Summer } & Unstable & 3.6 & $8.5 \pm 0.5$ & $19.8 \pm 1.7$ & $6.3 \pm 1.0$ \\
\hline & & Stable & & $98.3 \pm 8.5$ & $58.3 \pm 5.2$ & $8.8 \pm 0.8$ \\
\hline & \multirow[t]{2}{*}{ Winter } & Unstable & 0.4 & $17.5 \pm 4.8$ & $22.7 \pm 1.8$ & $7.4 \pm 0.6$ \\
\hline & & Stable & & $98.1 \pm 16.2$ & $50.4 \pm 2.4$ & $8.9 \pm 0.1$ \\
\hline
\end{tabular}

4.1, the average $R_{r}$ is $37 \mathrm{~s} \mathrm{~m}^{-1}$. It appears that the seasonal $L A I$ change alters the radiative property of the surface that is related to the radiometric resistance, but the exact nature of this property is not known.

For the coniferous forest site group, because the difference in the average $L A I$ between the summer and the winter season is very small, the seasonal difference in $R_{r}$ is greatly reduced (Table 2). The $L A I$ difference is not zero between summer and winter for this group because of the presence of deciduous understorey vegetation and deciduous trees at some of the coniferous sites.

The $R_{r}$ in the cropland group behaves similarly to in the deciduous forest group, showing much larger values in the winter than in the summer. The grassland/shrubland group, unlike the deciduous forest and cropland groups, shows little difference in $R_{r}$ between summer and winter under unstable conditions. This is because, for grassland, unless it is burned, dead vegetation is still standing at the surface, whereas for cropland there is a drastic difference in the vegetation stands between the growing and the nongrowing season.

\subsection{Daily Variations}

To further investigate the influence of $L A I$, we analyzed the daily variations of the radiometric resistance for a cropland site with continuous maize plantation, Mead irrigated site in Nebraska (site ID US-Ne1, Table 1). The growing season is from the beginning of June to the end of September. This irrigated cropland site has a more variable $L A I$ over the year compared with a typical forest or grassland site.

The patterns seen in the seasonal mean values across multiple sites still hold for the daily values at this specific site (Fig. 3). The multiyear data show obvious annual cycles of $R_{r}$, in the range from -20 to $330 \mathrm{~s} \mathrm{~m}^{-1}$ (Fig. 3a, b). As expected, the trend of the $R_{r}$ cycle is just opposite 

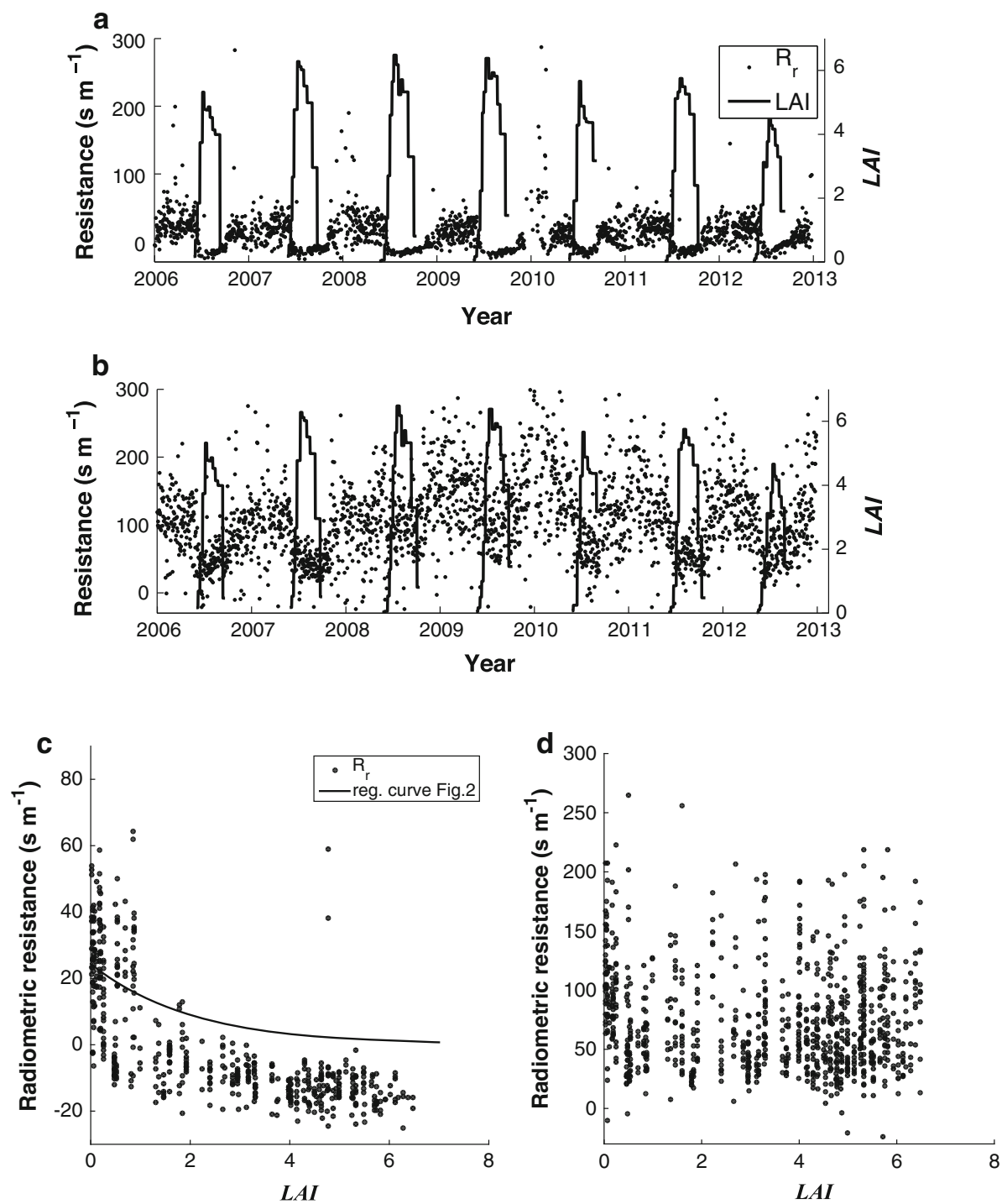

Fig. 3 Correlation between the daily radiometric resistance and $L A I$ at the Mead irrigated site in Nebraska (site ID US-Ne1): a time series under unstable conditions (daytime), b time series under stable conditions (nighttime), $\mathbf{c}$ scatter plot under unstable conditions, $\mathbf{d}$ scatter plot under stable conditions. Each dot in a and c represents an average value of all hourly data of a given day for which $H>5 \mathrm{~W} \mathrm{~m}^{-2}$; each dot in $\mathbf{b}$ and $\mathbf{d}$ represents an average value of all hourly data of a given day for which $H<-5 \mathrm{~W} \mathrm{~m}^{-2}$. The regression line is reproduced from Fig. 2 and represented by $y=24.4 \exp (-0.5 x)$

to the phase of the crop LAI cycle. The seasonal pattern is stronger under unstable conditions than under stable conditions, as is illustrated by the much clearer variations between the growing and nongrowing season in Fig. 3a than Fig. 3b. This is consistent with what was observed for the seasonal mean values at multiple sites (Fig. 2).

Under unstable conditions, the day-to-day variation is smaller than the contrast between the growing and the nongrowing season; For example, in the year 2008-2009, the standard devi- 
ation of the daily $R_{r}$ is $6 \mathrm{~s} \mathrm{~m}^{-1}$ for the growing season (10 June 2008-7 October 2008) under unstable conditions. For comparison, the mean difference between the two seasons is $57 \mathrm{~s} \mathrm{~m}^{-1}$ under unstable conditions. The day-to-day fluctuations were caused by variations in the site microclimatic conditions. Since the goal of this research is to better isolate the influences on the heat resistances of different land-surface types, these variations represent unwanted "random noise." By using seasonal mean values, these fluctuations were filtered out.

Under unstable conditions, the daily mean $R_{r}$ shows a pattern (Fig. $3 \mathrm{c}$ ) similar to the seasonal mean across the sites (Fig. 2a), that is, an exponential decay of $R_{r}$ with increasing LAI. Although the general pattern is similar to that seen for the seasonal mean values at multiple sites, the regression curve is different. The difference is caused by the negative radiometric resistance values that occurred persistently in the growing season (Fig. 3a, c). The two outliers in Fig. 3c probably result from measurement errors. These two dates are 12 July 2006 and 6 July 2007. For both days, only one valid hourly observation is available for calculating the resistance because, for all other hourly measurements, the sign of $\theta_{s}-\theta_{a}$ is opposite to the sign of $H$. Under stable conditions, this exponential decay relationship is no longer detectable (Fig. 3d). Instead, $R_{r}$ appears independent of $L A I$. The mean $R_{r}$ value is $105 \mathrm{~s} \mathrm{~m}^{-1}$.

Negative resistances are physically unacceptable. Two possible causes of the negative $R_{r}$ values at this site are contamination of the air temperature measurement by solar heating, and inaccurate $z_{0}$ parametrization. If $\theta_{a}$ is measured correctly, $\theta_{s}-\theta_{a}$ should be approximately zero when $H$ is $0 \mathrm{~W} \mathrm{~m}^{-2}$. However, the scatter plot of half-hourly $H$ versus $\theta_{s}-\theta_{a}$ for this site (Supplementary Fig. S1) reveals that, at $H=0$, the temperature difference $\theta_{s}-\theta_{a}$ has an offset of $1-1.5 \mathrm{~K}$, indicating a potential bias in the temperature measurement. One source of bias error is related to sunlight heating of the air temperature sensor. Another possible source of error is the temperature calibration. The manufacturer's original calibration, not necessarily still accurate, was used at this site. Indeed, reducing $\theta_{a}$ by $1 \mathrm{~K}$ would eliminate most of the negative $R_{r}$ values and bring the result into better agreement with the site mean regression curve (Fig. 4a).

Raupach (1994) showed that $z_{0}$ should respond dynamically to both canopy height and LAI. We thus parametrized $z_{0}$ as a function of canopy height and $L A I$ according to Raupach (1994)
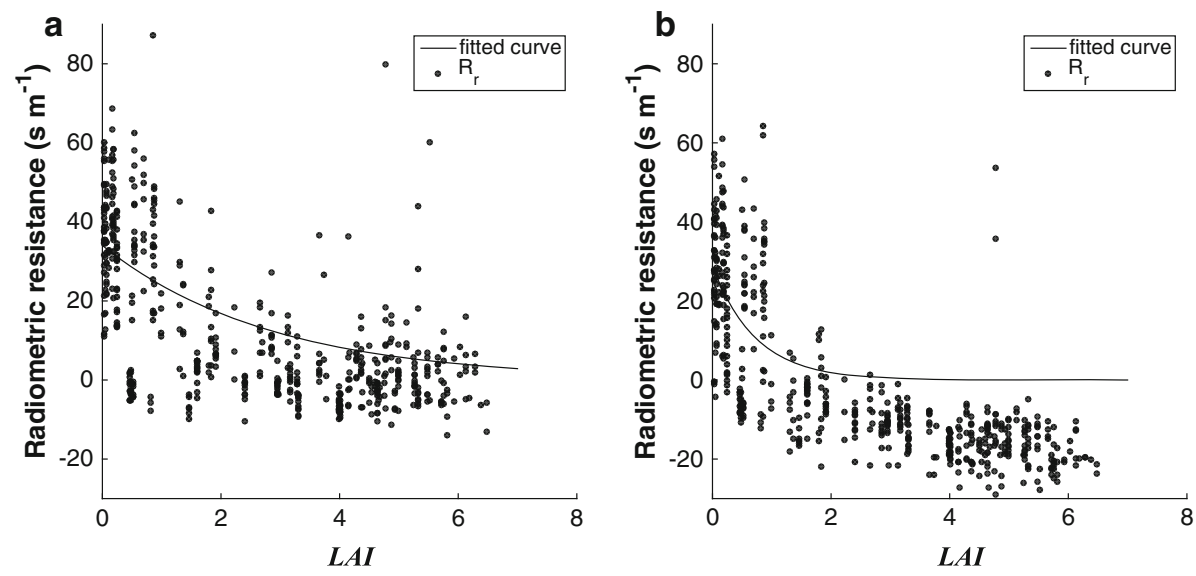

Fig. 4 Sensitivity analyses to air temperature bias and $z_{0}$ parameterization under unstable conditions for the Nebraska site: a $\theta_{a}$ reduced by $1 \mathrm{~K}$; b original $\theta_{a}, z_{0}=\exp (-2.3) h L A I^{-0.15}$ 
to determine whether the negative $R_{r}$ values may be caused by inaccurate $z_{0}$ parametrization. Comparison of this new result (Fig. $4 \mathrm{~b}$ ) with the calculation using fixed $z_{0}$ (Fig. 3c) shows that this dynamic parametrization has little effect on the negative $R_{r}$ values.

\subsection{Relations of Heat Resistances to Thermal Stability}

All the three component resistances are generally larger under stable conditions than under unstable conditions (Figs. 2, 5). Table 2 presents the average resistances across all sites under unstable and stable conditions and in the summer and the winter. Our results confirm that stable stratification tends to suppress heat transfer. This thermal stability effect has been known for a long time for aerodynamic resistance (Garratt 1994). According to our results, thermal stability has similar impacts on the radiometric resistance. Table 2 shows that $R_{r}$ is larger under stable conditions than under unstable conditions in each vegetation type group, and in both winter and summer. On average, summer $R_{r}$ is $68 \mathrm{~s} \mathrm{~m}^{-1}$ larger, and winter $R_{r}$ is $64 \mathrm{~s} \mathrm{~m}^{-1}$ larger under stable conditions than under unstable conditions for all the selected sites. It appears that stable stratification enlarges the distance between $z_{h}$ and $z_{r}$.

Under stable conditions, there is no apparent correlation between $L A I$ and the aerodynamic resistance (summer: $R^{2}<0.05$; winter: $R^{2}<0.01$ ), a pattern that is different from that observed in unstable conditions (summer: $R^{2}>0.58$; winter: $R^{2}>0.30$ ). Under stable conditions, $R_{r}$ shows no apparent correlation with $L A I$ either (Fig. 5a, b), and is on average $40 \mathrm{~s} \mathrm{~m}^{-1}$ larger than $R_{e x}$ in the summer and $65 \mathrm{~s} \mathrm{~m}^{-1}$ larger in the winter for all the sites examined in this study. The $R_{r}$ values are compatible with the $R_{r}$ estimates by Stewart et al. (1994) $\left(22-73 \mathrm{~s} \mathrm{~m}^{-1}\right)$. Under unstable conditions, the average $R_{r}$ is $8 \mathrm{~s} \mathrm{~m}^{-1}$, only slightly larger than $R_{\text {ex }}\left(5 \mathrm{~s} \mathrm{~m}^{-1}\right)$.

\subsection{Impacts of Radiometric Resistance on Sensible Heat Flux Calculation}

To assess the impacts of radiometric resistance on the sensible heat flux calculation, we first calculated the sensible heat flux using the complete Eq. 6 and again by omitting $R_{r}$ from Eq. 6, as

$$
\hat{H}=\rho C_{p} \frac{\theta_{s}-\theta_{a}}{R_{a}+R_{e x}} .
$$

In Eq. 6, $R_{r}$ was obtained from the regression fit functions of $L A I$ shown in Fig. 2a (summer) and $2 \mathrm{~b}$ (winter) for unstable conditions and constant values of $50 \mathrm{~s} \mathrm{~m}^{-1}$ (summer) and $66 \mathrm{~s} \mathrm{~m}^{-1}$ (winter) for stable conditions, and other terms were provided by field measurements. The prediction error $e$ and the relative prediction error $e_{r}$ are defined as

$$
\begin{aligned}
e & =\hat{H}-H, \\
e_{r} & =\frac{e}{H},
\end{aligned}
$$

where $H$ is the observed sensible heat flux.

Unsurprisingly, omission of $R_{r}$ results in an overestimation of the magnitude of the sensible heat flux. Under stable conditions, the prediction error has no apparent correlation with the site $L A I$. Under unstable conditions, the prediction error is much larger for low- $L A I$ sites than for high- $L A I$ sites (Fig. 6a). The relative error decreases as the $L A I$ increases under unstable conditions and has no apparent correlation with $L A I$ under stable conditions (Fig. 6b). These results show that the largest overestimation due to omission of $R_{r}$ occurs at low-LAI surfaces and under unstable conditions. 

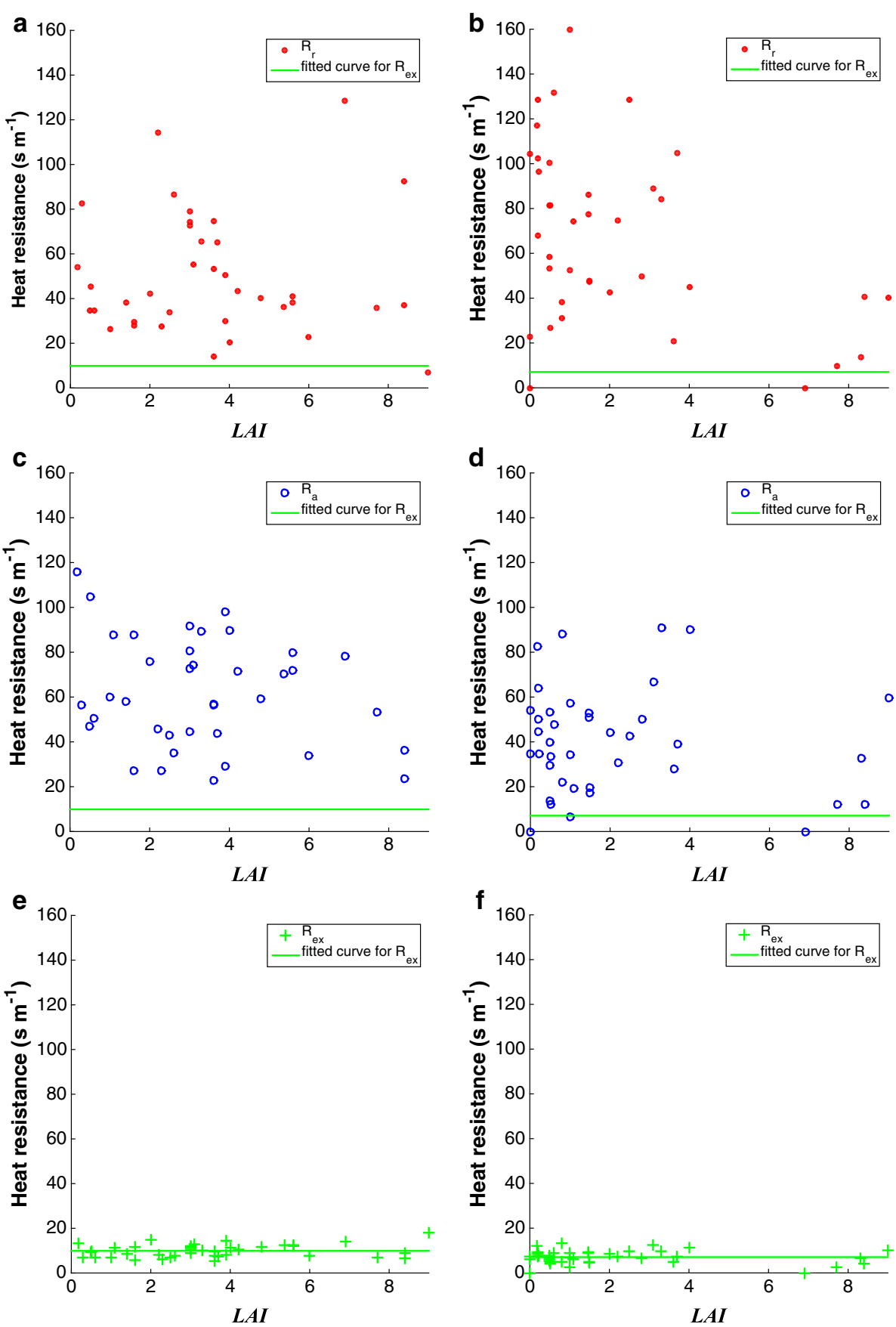

Fig. 5 Same as Fig. 2 but for stable conditions 
Fig. 6 Bin average prediction errors of sensible heat flux caused by omission of the radiometric resistance: top panel prediction error; bottom panel relative prediction error. Error bars denote 1 s.e.
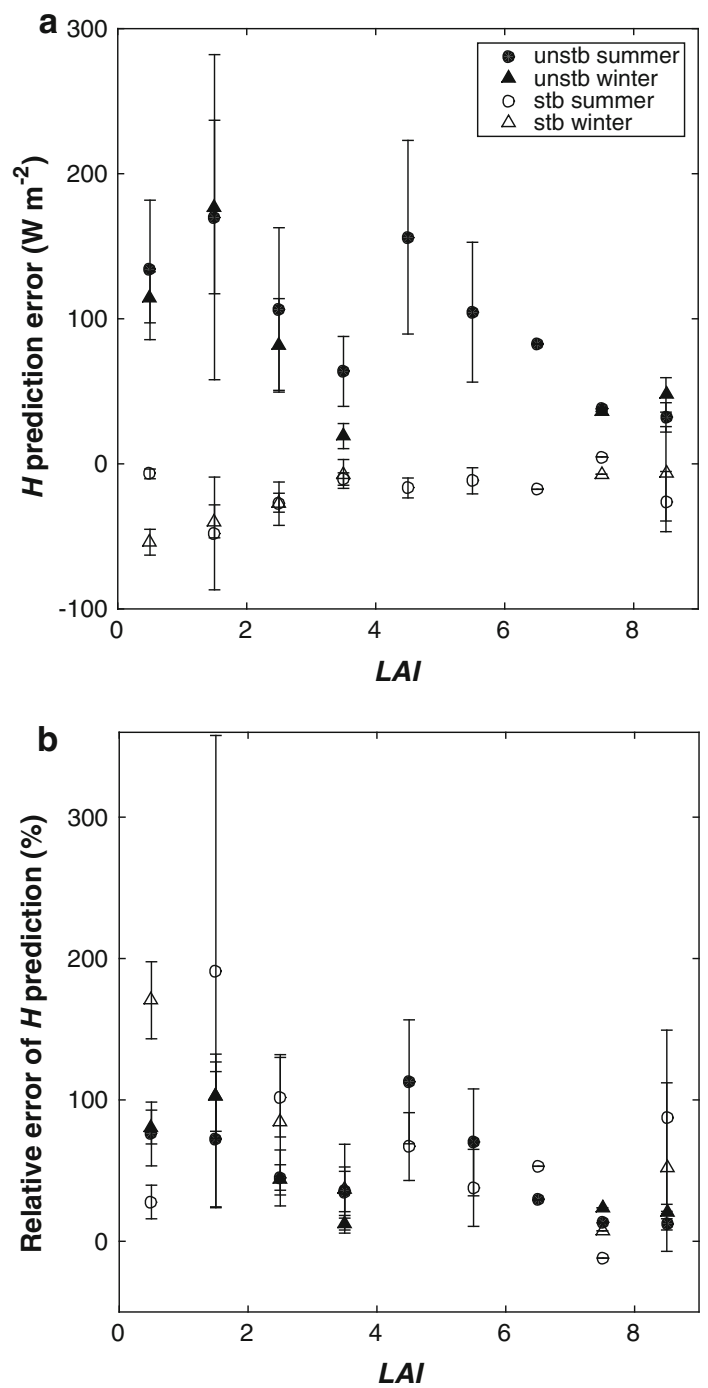

Similar results are found in the literature. In an experiment in a soybean field, Lee et al. (2009) reported larger prediction errors (up to $308 \mathrm{~W} \mathrm{~m}^{-2}$ ) for the early part of the growing season $(L A I<2)$ than in the middle part of the growing season (error $<15 \mathrm{~W} \mathrm{~m}^{-2}$ ) when the $L A I$ is large $(L A I=7.6)$. Chen and Zhang (2009) compared the observed heat transfer coefficient $C_{h}$ from Ameriflux sites and the modeled $C_{h}$ according to the Noah LSM, and reported large model overestimations for short vegetation. In the LSM, the two roughness values $\left(z_{h}\right.$ and $\left.z_{0}\right)$ are used to calculate $C_{h}$ without the radiometric resistance. Because $C_{h}$ is inversely proportional to the heat resistance, overestimation of $C_{h}$ indicates overestimation of $H$ in the model. Zheng et al. (2012) reported a large cold bias in the daytime $\theta_{s}$ (up to $-15^{\circ} \mathrm{C}$ ) produced by NCEP Global Forecast Modelling System operational modeling over the arid western continental USA, where $L A I$ is very small. In the Global Forecast System, $\theta_{S}$ is solved from the energy balance equation with $H$ parametrized according to Eq. 1 and with the 
approximation $\theta_{s}=\theta_{0 h}$. In other words, the default NCEP calculation omits the radiometric resistance. By adding the radiometric resistance as a function of vegetation fraction to the bulk formula, Zheng et al. (2012) significantly reduced the cold bias in $\theta_{s}$ (average bias $<-4{ }^{\circ} \mathrm{C}$ ). Similarly to our findings, they found that their $R_{r}$ formulation had a minimal effect on the nighttime $\theta_{S}$ under stable conditions. Recently, Zhang et al. (2014) also reported a large high bias $\left(120 \mathrm{~W} \mathrm{~m}^{-2}\right)$ in $H$ calculated with a $L A I$-independent parametrization of $z_{r}$ for a desert steppe site, and using a time-varying roughness length for heat as a function of vegetation growth reduced the root-mean-squared error of $H$ by more than half.

\section{Conclusions}

A simple resistance model was used to decompose the total resistance to heat transfer from the surface to a reference height into three additive components: radiometric resistance, excess resistance, and aerodynamic resistance. On average, all resistances are greater under stable conditions than under unstable conditions. The excess resistance shows no apparent relation to $L A I$ changes under both unstable and stable conditions. The aerodynamic and radiometric resistances decrease exponentially as $L A I$ increases under unstable conditions. Under stable conditions, the aerodynamic and radiometric resistances show no apparent relation to $L A I$ changes and are much larger than the excess resistance. Daily data from a cropland site show that the correlations with $L A I$ seen in the seasonal mean values across multiple sites still hold for the daily values. High bias in the sensible heat flux calculation occurs if the radiometric resistance is omitted from the bulk transfer formulation, with the overestimation larger at lower $L A I$. This problem is especially severe at low $L A I(<2)$ and under unstable conditions.

Acknowledgments This research was supported in part by the Ministry of Education of China (grant PCSIRT). The first author also acknowledges support by a Yale University graduate fellowship.

\section{References}

Baldocchi D, Vogel CA, Hall B (1997) Seasonal variation of energy and water vapor exchange rates above and below a boreal jack pine forest canopy. J Geophys Res 102(D24):28939-28951

Beljaars ACM, Holtslag AAM (1991) Flux parameterization over land surfaces for atmospheric models. J Appl Meteorol 30(3):327-341

Bergeron O, Margolis HA, Black TA, Coursolle C, Dunn AL, Barr AG, Wofsy SC (2007) Comparison of carbon dioxide fluxes over three boreal black spruce forests in Canada. Glob Change Biol 13(1):89-107

Blanken PD, Black TA, Yang PC, Neumann HH, Nesic Z, Staebler R, den Hartog G, Novak MD, Lee X (1997) Energy balance and canopy conductance of a boreal aspen forest: Partitioning overstory and understory components. J Geophys Res 102(D24):28915-28927

Brutsaert W (1992) Stability correction functions for the mean wind-speed and temperature in the unstable surface-layer. Geophys Res Lett 19(5):469-472

Brutsaert W, Sugita M (1992) Regional surface fluxes from satellite-derived surface temperatures (AVHRR) and radiosonde profiles. Bound-Layer Meteorol 58(4):355-366

Chen F, Zhang Y (2009) On the coupling strength between the land surface and the atmosphere: From viewpoint of surface exchange coefficients. Geophys Res Lett 36:L10404

Chen SP, Chen JQ, Lin GH, Zhang WL, Miao HX, Wei L, Huang JH, Han XG (2009) Energy balance and partition in Inner Mongolia steppe ecosystems with different land use types. Agric For Meteorol 149(11):1800-1809

Choudhury BJ, Reginato RJ, Idso SB (1986) An analysis of infrared temperature observations over wheat and calculation of latent-heat flux. Agric For Meteorol 37(1):75-88

Clark KL, Skowronski N, Hom J (2010) Invasive insects impact forest carbon dynamics. Glob Change Biol 16(1):88-101 
Coursolle C, Margolis HA, Barr AG, Black TA, Amiro BD, McCaughey JH, Flanagan LB, Lafleur PM, Roulet NT, Bourque CPA, Arain MA, Wofsy SC, Dunn A, Morgenstern K, Orchansky AL, Bernier PY, Chen JM, Kidston J, Saigusa N, Hedstrom N (2006) Late-summer carbon fluxes from Canadian forests and peatlands along an east-west continental transect. Can J Forest Res. 36(3):783-800

Davis KJ, Bakwin PS, Yi CX, Berger BW, Zhao CL, Teclaw RM, Isebrands JG (2003) The annual cycles of $\mathrm{CO}_{2}$ and $\mathrm{H}_{2} \mathrm{O}$ exchange over a northern mixed forest as observed from a very tall tower. Glob Change Biol 9(9):1278-1293

Dore S, Kolb TE, Montes-Helu M, Sullivan BW, Winslow WD, Hart SC, Kaye JP, Koch GW, Hungate BA (2008) Long-term impact of a stand-replacing fire on ecosystem $\mathrm{CO}(2)$ exchange of a ponderosa pine forest. Glob Change Biol 14(8):1801-1820

Fischer ML, Billesbach DP, Berry JA, Riley WJ, Torn MS (2007) Spatiotemporal variations in growing season exchanges of $\mathrm{CO}_{2}, \mathrm{H}_{2} \mathrm{O}$, and sensible heat in agricultural fields of the Southern Great Plains. Earth Interact 11(17):1-21

Garratt JR (1994) The atmospheric boundary layer. Cambridge University Press, Cambridge, 336 pp

Garratt JR, Hicks BB (1973) Momentum, heat and water vapour transfer to and from natural and artificial surfaces. Q J R Meteorol Soc 99(422):680-687

Garratt JR, Francey R (1978) Bulk characteristics of heat transfer in the unstable, baroclinic atmospheric boundary layer. Bound-Layer Meteorol 15(4):399-421

Gilmanov TG, Tieszen LL, Wylie BK, Flanagan LB, Frank AB, Haferkamp MR, Meyers TP, Morgan JA (2005) Integration of $\mathrm{CO}_{2}$ flux and remotely-sensed data for primary production and ecosystem respiration analyses in the Northern Great Plains: potential for quantitative spatial extrapolation. Glob Ecol Biogeogr 14(3):271-292

Gu LH, Meyers T, Pallardy SG, Hanson PJ, Yang B, Heuer M, Hosman KP, Riggs JS, Sluss D, Wullschleger SD (2006) Direct and indirect effects of atmospheric conditions and soil moisture on surface energy partitioning revealed by a prolonged drought at a temperate forest site. J Geophys Res 111(D16):D16102

Hall FG, Huemmrich KF, Goetz SJ, Sellers PJ, Nickeson JE (1992) Satellite remote-sensing of surface-energy balance-success, failures, and unresolved issues in fife. J Geophys Res 97(D17):19061-19089

Hollinger DY, Aber J, Dail B, Davidson EA, Goltz SM, Hughes H, Leclerc MY, Lee JT, Richardson AD, Rodrigues C, Scott NA, Achuatavarier D, Walsh J (2004) Spatial and temporal variability in forestatmosphere CO2 exchange. Glob Change Biol 10(10):1689-1706

Hollinger DY, Goltz SM, Davidson EA, Lee JT, Tu K, Valentine HT (1999) Seasonal patterns and environmental control of carbon dioxide and water vapour exchange in an ecotonal boreal forest. Glob Change Biol 5(8):891-902

Hollinger DY, Ollinger SV, Richardson AD, Meyers TP, Dail DB, Martin ME, Scott NA, Arkebauer TJ, Baldocchi DD, Clark KL, Curtis PS, Davis KJ, Desai AR, Dragoni D, Goulden ML, Gu L, Katul GG, Pallardy SG, Paw KT, Schmid HP, Stoy PC, Suyker AE, Verma SB (2010) Albedo estimates for land surface models and support for a new paradigm based on foliage nitrogen concentration. Glob Change Biol 16(2):696-710

Hollinger SE, Bernacchi CJ, Meyers TP (2005) Carbon budget of mature no-till ecosystem in North Central Region of the United States. Agric For Meteorol 130(1-2):59-69

Humphreys ER, Black TA, Ethier GJ, Drewitt GB, Spittlehouse DL, Jork EM, Nesic Z, Livingston NJ (2003) Annual and seasonal variability of sensible and latent heat fluxes above a coastal Douglas-fir forest, British Columbia, Canada. Agric For Meteorol 115(1-2):109-125

Humphreys ER, Black TA, Morgenstern K, Cai TB, Drewitt GB, Nesic Z, Trofymow JA (2006) Carbon dioxide fluxes in coastal Douglas-fir stands at different stages of development after clearcut harvesting. Agric For Meteorol 140(1-4):6-22

Jarvis PG, Massheder JM, Hale SE, Moncrieff JB, Rayment M, Scott SL (1997) Seasonal variation of carbon dioxide, water vapor, and energy exchanges of a boreal black spruce forest. J Geophys Res 102(D24):28953-28966

Krishnan P, Meyers TP, Scott RL, Kennedy L, Heuer M (2012) Energy exchange and evapotranspiration over two temperate semi-arid grasslands in North America. Agric For Meteorol 153:31-44

Kustas WP, Anderson M (2009) Advances in thermal infrared remote sensing for land surface modeling. Agric For Meteorol 149(12):2071-2081

Kustas WP, Anderson MC, Norman JM, Li F (2007) Utility of radiometric-aerodynamic temperature relations for heat flux estimation. Bound-Layer Meteorol 122(1):167-187

Kustas WP, Choudhury BJ, Moran MS, Reginato RJ, Jackson RD, Gay LW, Weaver HL (1989) Determination of sensible heat-flux over sparse canopy using thermal infrared data. Agric For Meteorol 44(3-4):197-216

Kustas WP, Jackson T, Prueger J, Hatfield J, Anderson M (2003) Remote sensing field experiments evaluate retrieval algorithms and land-atmosphere modeling. Eos Trans Amer Geophys Union 84(45):485-493 
Law BE, Turner D, Campbell J, Sun OJ, Van Tuyl S, Ritts WD, Cohen WB (2004) Disturbance and climate effects on carbon stocks and fluxes across Western Oregon USA. Glob Change Biol 10(9):1429-1444

Lee XH, Griffis TJ, Baker JM, Billmark KA, Kim K, Welp LR (2009) Canopy-scale kinetic fractionation of atmospheric carbon dioxide and water vapor isotopes. Glob Biogeochem Cycles. 23:GB1002

Lhomme JP, Katerji N, Perrier A, Bertolini JM (1988) Radiative surface-temperature and convective flux calculation over crop canopies. Bound-Layer Meteorol 43(4):383-392

Ma SY, Baldocchi DD, Xu LK, Hehn T (2007) Inter-annual variability in carbon dioxide exchange of an oak/grass savanna and open grassland in California. Agric For Meteorol 147(3-4):157-171

Mahrt L, Vickers D (2002) Relationship of area-averaged carbon dioxide and water vapour fluxes to atmospheric variables. Agric For Meteorol 112(3-4):195-202

Mahrt L, Vickers D (2004) Bulk formulation of the surface heat flux. Bound-Layer Meteorol 110(3):357-379

Massman WJ (2000) A simple method for estimating frequency response corrections for eddy covariance systems. Agric For Meteorol 104(3):185-198

Matsushima D (2005) Relations between aerodynamic parameters of heat transfer and thermal-infrared thermometry in the bulk surface formulation. J Meteorol Soc Jpn 83(3):373-389

McNaughton KG, Vandenhurk BJJM (1995) A lagrangian revision of the resistors in the 2-layer model for calculating the energy budget of a plant canopy. Bound-Layer Meteorol 74(3):261-288

Molder M, Lindroth A (2001) Dependence of $\mathrm{kB}^{-1}$ factor on roughness Reynolds number for barley and pasture. Agric For Meteorol 106(2):147-152

Monson RK, Turnipseed AA, Sparks JP, Harley PC, Scott-Denton LE, Sparks K, Huxman TE (2002) Carbon sequestration in a high-elevation, subalpine forest. Glob Change Biol 8(5):459-478

Monteith JL (1973) Principles of environmental physics. American Elsevier Publications, New York

Mu QZ, Zhao MS, Running SW (2011) Improvements to a MODIS global terrestrial evapotranspiration algorithm. Remote Sens Environ 115(8):1781-1800

Noormets A, Gavazzi MJ, McNulty SG, Domec JC, Sun G, King JS, Chen JQ (2010) Response of carbon fluxes to drought in a coastal plain loblolly pine forest. Glob Change Biol 16(1):272-287

Raupach MR (1994) Simplified expressions for vegetation roughness length and zero-plane displacement as functions of canopy height and area index. Bound-Layer Meteorol 71(1-2):211-216

Schmid HP, Grimmond CSB, Cropley F, Offerle B, Su HB (2000) Measurements of $\mathrm{CO}_{2}$ and energy fluxes over a mixed hardwood forest in the mid-western United States. Agric For Meteorol 103(4):357-374

Schmid HP, Su HB, Vogel CS, Curtis PS (2003) Ecosystem-atmosphere exchange of carbon dioxide over a mixed hardwood forest in northern lower Michigan. J Geophys Res 108(D14):4417

Schmidt A, Hanson C, Kathilankal J, Law BE (2011) Classification and assessment of turbulent fluxes above ecosystems in North-America with self-organizing feature map networks. Agric For Meteorol 151(4):508-520

Scott RL, Jenerette GD, Potts DL, Huxman TE (2009) Effects of seasonal drought on net carbon dioxide exchange from a woody-plant-encroached semiarid grassland. J Geophys Res 114:G04004

Stewart JB, Kustas WP, Humes KS, Nichols WD, Moran MS, Debruin HAR (1994) Sensible heat-flux radiometric surface-temperature relationship for 8 semiarid areas. J Appl Meteorol 33(9):1110-1117

Su Z, Schmugge T, Kustas WP, Massman WJ (2001) An evaluation of two models for estimation of the roughness height for heat transfer between the land surface and the atmosphere. J Appl Meteorol 40(11):1933-1951

Sugita M, Brutsaert W (1990) Regional surface fluxes from remotely sensed skin temperature and lower boundary-layer measurements. Water Resour Res 26(12):2937-2944

Sun JL, Mahrt L (1995) Determination of surface fluxes from the surface radiative temperature. J Atmos Sci 52(8):1096-1106

Suyker AE, Verma SB, Burba GG, Arkebauer TJ (2005) Gross primary production and ecosystem respiration of irrigated maize and irrigated soybean during a growing season. Agric For Meteorol 131(3-4):180-190

Suyker AE, Verma SB, Burba GG, Arkebauer TJ, Walters DT, Hubbard KG (2004) Growing season carbon dioxide exchange in irrigated and rainfed maize. Agric For Meteorol 124(1-2):1-13

Syed KH, Flanagan LB, Carlson PJ, Glenn AJ, Van Gaalen KE (2006) Environmental control of net ecosystem $\mathrm{CO}_{2}$ exchange in a treed, moderately rich fen in northern Alberta. Agric For Meteorol 140(1-4):97-114

Thom AS (1972) Momentum, mass and heat-exchange of vegetation. Q J R Meteorol Soc 98(415):124-134

Thom AS, Stewart JB, Oliver HR, Gash JHC (1975) Comparison of aerodynamic and energy budget estimates of fluxes over a pine forest. Q J R Meteorol Soc 101(427):93-105

Thornton PE, Law BE, Gholz HL, Clark KL, Falge E, Ellsworth DS, Golstein AH, Monson RK, Hollinger D, Falk M, Chen J, Sparks JP (2002) Modeling and measuring the effects of disturbance history and climate on carbon and water budgets in evergreen needleleaf forests. Agric For Meteorol 113(1-4):185-222 
Troufleau D, Lhomme JP, Monteny B, Vidal A (1997) Sensible heat flux and radiometric surface temperature over sparse Sahelian vegetation.1. An experimental analysis of the kB(-1) parameter. J Hydrol 189(14):815-838

Verhoef A, DeBruin HAR, VandenHurk BJJM (1997) Some practical notes on the parameter kB(-1) for sparse vegetation. J Appl Meteorol 36(5):560-572

Vickers D, Thomas C, Law BE (2009) Random and systematic $\mathrm{CO}_{2}$ flux sampling errors for tower measurements over forests in the convective boundary layer. Agric For Meteorol 149(1):73-83

Voogt JA, Grimmond CSB (2000) Modeling surface sensible heat flux using surface radiative temperatures in a simple urban area. J Appl Meteorol 39(10):1679-1699

Wilson KB, Meyers TP (2001) The spatial variability of energy and carbon dioxide fluxes at the floor of a deciduous forest. Bound-Layer Meteorol 98(3):443-473

Wilson TB, Meyers TP (2007) Determining vegetation indices from solar and photosynthetically active radiation fluxes. Agric For Meteorol 144(3-4):160-179

Yang K, Koike T, Yang DW (2003) Surface flux parameterization in the Tibetan Plateau. Bound-Layer Meteorol 106(2):245-262

Zhang G, Zhou GS, Chen F, Barlage M, Xue LL (2014) A trial to improve surface heat exchange simulation through sensitivity experiments over a desert steppe site. J Hydrometeorol 15(2):664-684

Zheng WZ, Wei HL, Wang Z, Zeng XB, Meng J, Ek M, Mitchell K, Derber J (2012) Improvement of daytime land surface skin temperature over arid regions in the NCEP GFS model and its impact on satellite data assimilation. J Geophys Res 117:D06117 